\title{
FARELO DE GÉRMEN DE MILHO DESENGORDURADO ASSOCIADO À FITASE
}

\author{
DEFATTED CORN GERM MEAL ASSOCIATED WITH PHYTASE IN THE DIET
}

\author{
Pacheco, G.D. ${ }^{1}$, Lozano, A.P. ${ }^{2}$, Vinokurovas, S.L. ${ }^{2}$, Silva, R.A.M. ${ }^{2}$, Dalto, D.B. ${ }^{2}$, \\ Agostini, P.S. ${ }^{3}$, Westphalen, N. ${ }^{2}$, Bridi, A.M. ${ }^{1}$ e Silva, C.A. ${ }^{1}$
}

\begin{abstract}
1'Departamento de Zootecnia. Universidade Estadual de Londrina. Londrina-PR. Brasil. casilva@uel.br ${ }^{2}$ Programa de Pós-Graduação em Ciência Animal. Universidade Estadual de Londrina. Londrina-PR. Brasil. grazivetuel@yahoo.com.br
\end{abstract}

${ }^{3}$ Departament de Ciència Animal i dels Aliments. Universitat Autònoma de Barcelona. Barcelona. España.

\section{PaLAVRAS ChaVE ADICIONAIS}

Ácido fítico. Antioxidante. Enzima.

\section{RESUMO}

O objetivo do trabalho foi avaliar a influência e a possível interação entre o ácido fítico, veiculado na ração de suínos em fase de terminação, principalmente pelo farelo de gérmen de milho desengordurado (FGMD), e a fitase sobre os parâmetros de desempenho, perfil sérico e características de carcaça. Foram utilizados 32 suínos de linhagem comercial Pen ArLancom 60,31 $\pm 5,32$ $\mathrm{kg}$ de peso vivo inicial. Os animais receberam água e ração à vontade durante os 29 dias de experimento, sendo computados o consumo diário de ração, o ganho diário de peso e a conversão alimentar. No 14 dia coletou-se sangue para hemograma e avaliação das concentrações sérica de fósforo, cálcio, ferro, triglicérides, colesterol e uréia. Determinou-se os teores de fósforo e cálcio nas fezes. O FGMD, como principal fonte de ácido fítico na ração, promoveu maior consumo de ração pelos animais. As demais variáveis de desempenho, carcaça e parâmetros hematológicos não foram influenciadas pelos fatores FGMD e fitase. Machos castrados apresentaram maior excreção de uréia, maiores pesos de carcaça e espessura de toucinho. Fêmeas apresentaram maior rendimento de carne na carcaça. A utilização da enzima fitase na ração foi efetiva na redução da excreção de fósforo e cálcio pelas fezes. Dietas com maior concentração de ácido fítico (com FGMD como ingrediente) não comprometeram as características avaliadas.

\author{
AdDitionAL KEYWORDS \\ Antioxidant. Enzyme. Phytic acid.
}

\section{SUMMARY}

The objective of this study was to evaluate the effect and the interaction of phytic acid (used in fattening pig diets, mainly through of defatted corn germ meal (FGMD)), and phytase on performance, serum profile and carcass traits. Thirty two pigs from a commercial line Pen Ar Lan averaging $60.31 \pm 5.32 \mathrm{~kg}$ (SD) of initial body weight were used. Animals were fed ad libitum during 29 days and it was measured the average daily feed intake, average daily gain and feed conversion ratio. Blood samples were taken at $14^{\text {th }}$ day of the experiment and a complete blood count and serum phosphorus, calcium, iron, triglycerides, cholesterol and urea concentrations were performed. Levels of phosphorus and calcium in faeces also were evaluated. A greater feed intake was observed when FGMD was included in the diets $(p<0.05)$. However, the other performance variables, carcass and hematological parameters were not influenced by both FGMD and phytase factors $(p \leq 0.05)$. Barrows had a greater urea excretion, carcass weight and backfat thickness than females $(p<0.05)$. In other hand, females had a greater meat yield of the chilled carcass compared to barrows $(p<0.05)$. Finally, when the phytase was added on feed, pigs had a lower level of phosphorus and calcium in faeces $(p<0.05)$. In conclusion, diets containing higher levels of phytic acid (with FGMD as ingredient) did not affect the parameters studied.

Arch. Zootec. 61 (236): 599-610. 2012. 


\section{PACHECO ETAL.}

\section{INTRODUÇÃO}

A poluição ambiental causada pelo excesso de minerais provenientes dos dejetos animais e a limitação do uso das fontes minerais não renováveis representam uma grande preocupação na produção sustentável de suínos. Nos últimos anos, formas de minimizar a excreção do fósforo pelas fezes dos suínos foram exploradas em razão do impacto negativo da contaminação de mananciais nas zonas de alta densidade animal (Castillon, 2005).

O fósforo, na forma de fitato ou ácido fítico, é a principal forma de reserva deste mineral nos grãos, sendo estocado principalmente na camada aleurona e no gérmen da semente (Bohn et al., 2008). No farelo de gérmen de milho desengordurado, um coproduto da industrialização do milho, o ácido fítico encontra-se em elevada concentração.

O ácido fítico possui elevado poder de quelação, com alta afinidade pelos cátions polivalentes cálcio, ferro, zinco, cobre e manganês, interferindo na biodisponibilidade desses minerais (Selle et al., 2000), que, não estando na forma ionizada, apresentam limitada absorção pelo organismo do animal (Lopez et al., 2002).

Todavia, a digestibilidade dos minerais pode ser aumentada com a adição de fitase microbiana às rações (Pointillart, 1997; Fireman e Fireman, 1998), melhorando, em algumas situações, a performance de animais alimentados com níveis adequados de fósforo. Ao mesmo tempo, é possível que as fitases também atuem sobre a utilização de outros nutrientes. Esse efeito, denominado extra-fosfórico, corresponde à maior disponibilidade de minerais e à melhor utilização de proteínas, aminoácidos e energia pelos animais.

Inúmeros fatores influenciam a eficácia das fitases microbianas, entre eles os níveis de substrato da dieta, a taxa de inclusão de fitase e o tipo de fitase utilizada (Selle e Ravindran, 2008). Estudos demonstram que a utilização da enzima pode reduzir a excreção total de fósforo em 30 a $50 \%$. Assim, os principais benefícios das fitases seriam poupar as reservas não renováveis de fósforo inorgânico e proteger o ambiente da poluição por excesso de minerais nos dejetos (Lei e Porres, 2003).

Diante desses fatores, o objetivo deste trabalho foi avaliar a influência e a possível interação entre a enzima fitase e o ácido fítico, presente sob maior concentração em dietas formuladas com $40 \%$ de farelo de gérmen de milho desengordurado (FGMD), sobre os parâmetros de desempenho, perfil sérico e características de carcaça de suínos em fase de terminação.

\section{MATERIALEMÉTODOS}

O experimento de desempenho foi conduzido no Setor de Suinocultura da Fazenda Escola da Universidade Estadual de Londrina. As análises foram realizadas no Laboratório de Patologia Clínica do Departamento de Medicina Veterinária Preventiva, Laboratório de Análise de Alimentos e Nutrição Animal (LANA) do Departamento de Zootecnia e Laboratório de Solos do Departamento de Agronomia da Universidade Estadual de Londrina.

Foram utilizados 32 suínos de linhagem comercial Pen Ar Lan, sendo 16 machos castrados e 16 fêmeas, com peso médio inicial \pm desvio padrão de $60,31 \pm 5,32 \mathrm{~kg}$. Os animais foram alojados individualmente em baias de alvenaria, com piso compacto e área de $3 \mathrm{~m}^{2}$, equipadas com comedouros metálicos semi-automáticos e bebedouros tipo nipple.

O delineamento experimental utilizado foi o de blocos casualizados, de acordo com o peso dos animais, num modelo fatorial 2 × 2 × 2 sendo os fatores: dietas sem inclusão de FGMD e com inclusão de $40 \%$ de FGMD, dietas sem inclusão de fitase e com inclusão de 1000 FTU, machos castrados e fêmeas. Cada animal foi considerado uma unidade experimental. 


\section{ÁCIDO FÍTICO E FITASE NA DIETA DE SUÍNOS}

Os animais receberam água e ração à vontade durante os 29 dias de período experimental. As rações foram formuladas visando atender às exigências nutricionais mínimas para a fase de terminação estabelecidas pelo NRC (1998), sendo isoenergéticas, isolisina, isometionina e isoprotéicas. Como fonte de fitase, utilizou-se o produto comercial Natuphós ${ }^{\circledR} 5000$.

Os ingredientes, a composição percen- tual e os valores calculados das dietas experimentais encontram-se na tabela $\mathbf{I}$.

Os suínos foram pesados semanalmente. Posteriormente, foram calculados o consumo diário de ração, o ganho diário de peso e a conversão alimentar dos animais.

No 14 dia do experimento foi realizada coleta de sangue, por punção da veia jugular. O sangue foi distribuído em frascos com o anticoagulante EDTA a $10 \%$ (etilenodia-

Tabela I. Composição percentual, química e energética das dietas experimentais. (Chemical and energy composition of the experimental diets).

\begin{tabular}{|c|c|c|c|c|}
\hline \multirow[b]{2}{*}{ Ingredientes (\%) } & \multicolumn{4}{|c|}{ Dietas } \\
\hline & $\begin{array}{l}\text { Sem FGMD/ } \\
\text { sem fitase }\end{array}$ & $\begin{array}{l}\text { SemFGMD/ } \\
\text { com fitase }\end{array}$ & $\begin{array}{l}\text { ComFGMD/ } \\
\text { sem fitase }\end{array}$ & $\begin{array}{r}\text { ComFGMD/ } \\
\text { com fitase }\end{array}$ \\
\hline FGMD $^{1}$ & - & - & 40,00 & 40,00 \\
\hline Milho grão & 72,34 & 72,36 & 38,46 & 38,03 \\
\hline Farelo de soja & 20,18 & 20,18 & 15,80 & 15,87 \\
\hline Óleo de soja & 1,20 & 1,20 & 3,18 & 3,34 \\
\hline Núcleo suíno² & 2,00 & 2,00 & 2,00 & 2,00 \\
\hline Sal & 0,30 & 0,30 & 0,30 & 0,30 \\
\hline Fosfato bicálcico & - & - & 0,19 & 0,19 \\
\hline L-Lisina-HCl & - & - & 0,07 & 0,07 \\
\hline Fitase $(1000 \mathrm{FTU})^{3}$ & - & 0,20 & - & 0,20 \\
\hline Inerte & 3,98 & 3,76 & - & - \\
\hline Total & 100 & 100 & 100 & 100 \\
\hline \multicolumn{5}{|l|}{ Valores calculados } \\
\hline Energia metabolizável (kcal/kg) & 3,142 & 3,142 & 3,142 & 3,142 \\
\hline Fibra bruta (\%) & 3,99 & 3,92 & 3,49 & 3,49 \\
\hline Fósforo disponível (\%) & 0,25 & 0,25 & 0,25 & 0,250 \\
\hline Fósforo total (\%) & 0,45 & 0,45 & 0,58 & 0,58 \\
\hline Cálcio (\%) & 0,69 & 0,69 & 0,74 & 0,74 \\
\hline Sódio (\%) & 0,16 & 0,16 & 0,14 & 0,14 \\
\hline Lisina (\%) & 0,75 & 0,75 & 0,75 & 0,75 \\
\hline Metionina (\%) & 0,25 & 0,25 & 0,25 & 0,25 \\
\hline Proteína bruta (\%) & 15,50 & 15,50 & 15,50 & 15,50 \\
\hline Gordura (\%) & 3,87 & 3,87 & 4,82 & 4,94 \\
\hline Ácido fítico $(\%)^{4}$ & 2,98 & 2,98 & 4,85 & 4,85 \\
\hline
\end{tabular}

Archivos de zootecnia vol. 61, núm. 236, p. 601. 


\section{PACHECO ETAL.}

minotetracético-potássico) para obtenção do plasma, e sem anticoagulante para obtenção do soro. As amostras com anticoagulante foram submetidas à contagem de hemácias, determinação da concentração de hemoglobina e volume globular. A contagem total de hemácias foi realizada por meio da técnica do hemocitômetro, a concentração da hemoglobina pelo método da cianometahemoglobina, e a determinação do volume globular por meio do microhematócrito. $\mathrm{O}$ soro foi armazenado à temperatura de $-20{ }^{\circ} \mathrm{C}$ até o momento do processamento, sendo determinadas as concentrações séricas de fósforo, cálcio, ferro, triglicérides, colesterol e uréia, por meio de kits enzimáticos colorimétricos Analisa $^{\circledR} \mathrm{e}$ a determinação realizada por meio do analisador bioquímico colorimétrico Airone $200^{\circledR}$.

Para determinação de fósforo e cálcio das fezes, foi realizada a técnica de coleta parcial de fezes, com a utilização do óxido crômico $(0,3 \%)$ como marcador fecal, quando os animais atingiram o peso médio de $76,25 \pm 8,18 \mathrm{~kg}$. As rações marcadas foram oferecidas aos suínos e após três dias de consumo, as fezes foram coletadas e armazenadas em sacos plásticos e mantidas em temperatura de congelamento. Posteriormente, as fezes foram descongeladas, secas em estufa de ventilação forçada a $60{ }^{\circ} \mathrm{C}$ por três dias e trituradas. Em seguida, foram encaminhadas ao laboratório para análise de fósforo e calcio, acordo com a técnica proposta por Malavolta et al. (1992) e Silva (1999).

O manejo pré-abate consistiu da retirada da ração 12 horas antes do embarque, permanecendo os animais em dieta hídrica até o abate.

Os animais foram abatidos com 141 dias de idade em frigorífico comercial localizado a $45 \mathrm{~km}$ da cidade de Londrina, pesando em média \pm desvio padrão $87,19 \pm 7,08 \mathrm{~kg}$ de peso vivo. $\mathrm{O}$ processo de abate consistiu primeiramente em uma insensibilização via corrente elétrica, com o equipamento da marca Petrovina IS 2000 com dois eletrodos, utilizando-se 350 volts e 1,3 ampères. $O$ choque elétrico foi aplicado por um período de aproximadamente três segundos. A sangria foi realizada por meio do corte dos vasos do pescoço, com os animais na posição vertical, suspensos pelo membro posterior. Após o abate, escaldagem e evisceração, as carcaças foram divididas ao meio longitudinalmente e resfriadas à temperatura de $21^{\circ} \mathrm{C}$, por 24 horas, na câmara de resfriamento do frigorífico.

As carcaças foram avaliadas individualmente de acordo com as orientações de Bridi e Silva (2007), onde foram obtidos os dados de comprimento de carcaça (CC), espessura de toucinho (ET), profundidade do músculo (PM), área de olho do lombo (AOL), peso da carcaça quente (PCQ), peso da carcaça fria (PCF) e rendimento de carcaça (RC). A espessura de toucinho e a profundidade do músculo Longissimus dorsi foram medidas na altura da última costela a $6 \mathrm{~cm} \mathrm{da}$ linha média do corte. A partir dos valores dessas medidas, estimou-se o rendimento de carne na carcaça (RCC), de acordo com a metodologia estabelecida por Guidoni (2000).

Os resultados foram submetidos à análise de variância e as médias comparadas pelo teste de Tukey utilizando-se o programa SAEG(1997).

\section{RESULTADOSEDISCUSSÃO}

Avaliando-se o fator FGMD, observase que somente o parâmetro consumo diário de ração apresentou-se diferente, sendo maior $(\mathrm{p}<0,05)$ para os animais que receberam dietas com FGMD conforme a tabela II. Não houve interação entre os fatores.

O maior consumo do FGMD pelos animais pode ser devido à maior palatabilidade do farelo, em relação às dietas sem o co-produto. Segundo Freitas (1998) o gérmen de milho possui boa palatabilidade, sendo facilmente consumido pelos suínos.

Harbach et al. (2007) também verificaram 


\section{ÁCIDO FÍTICO E FITASE NA DIETA DE SUÍNOS}

Tabela II. Médias e (desvios-padrão) das variáveis consumo diário de ração (CDR), ganho diário de peso (GDP) e conversão alimentar (CA) de suínos submetidos a tratamentos com e sem farelo de gérmen de milho desengordurado (FGMD) e com e sem fitase. (Means and (standard deviations) of the average daily feed intake (CDR), average daily gain (GDP) and feed conversion ratio (CA) in pigs fed with and without defatted corn germ meal (FGMD) and with and without phytase).

\begin{tabular}{lccc}
\hline Fatores & CDR $(\mathrm{kg})$ & Garâmetros \\
\hline SemFGMD & $2,36(0,4)^{\mathrm{b}}$ & $0,91(0,1)$ & $2,64(0,5)$ \\
ComFGMD & $2,59(0,2)^{\mathrm{a}}$ & $0,95(0,1)$ & $2,75(0,2)$ \\
& & & \\
Sem fitase & $2,43(0,4)$ & $0,92(0,1)$ & $2,68(0,5)$ \\
Com fitase & $2,52(0,3)$ & $0,93(0,1)$ & $2,70(0,2)$ \\
M. castrados & $2,65(0,3)^{\mathrm{a}}$ & $0,97(0,1)$ & $2,75(0,4)$ \\
Fêmeas & $2,30(0,2)^{\mathrm{b}}$ & $0,89(0,1)$ & $2,63(0,4)$ \\
CV (\%) & 12,8 & 10,8 & 11,9 \\
\hline
\end{tabular}

abLetras distintas nas colunas, para cada fator, indicam diferença $(p<0,05)$.

que a inclusão de FGMD entre 0 a $40 \%$ não resultou em diferença $(p>0,05)$ para nenhum dos parâmetros de desempenho avaliados.

Em relação ao fator fitase, não houve diferença entre os tratamentos para as características de desempenho. Todavia, contrário aos resultados obtidos, Beers e Jongbloed (1992), utilizando 1450 FTU/kg em rações de suínos, observaram $8,5 \%$ de aumento no consumo de ração e melhora de $4,4 \%$ na conversão alimentar. A suplementação da ração de suínos em crescimento com 1000 FTU por Ketaren et al. (1993), também determinou melhora na conversão alimentar dos animais.

Utilizando rações com e sem fitase (1000 FTU) e com e sem antioxidante (vitamina E), Gebert et al. (1999) também observaram que o fator fitase foi responsável por aumento no consumo de ração $(\mathrm{p}<0,01)$, aumento no ganho de peso $(\mathrm{p}<0,001)$ e melhora na conversão alimentar dos animais $(\mathrm{p}<0,01)$. Silva et al. (2004) concluíram que a utilização da enzima fitase (1250 FTU) em rações à base de milho, farelo de soja e farelo de arroz desengordurado melhorou a conversão alimentar dos suínos, decorrente da maior utilização dos nutrientes da ração.

Selle e Ravindran (2008) tratam que existem vários fatores que podem influenciar a eficiência das fitases microbianas, destacando os níveis de substrato da dieta, a taxa de inclusão de fitase e o tipo de fitase utilizada.

Em relação ao fator gênero, machos castrados apresentaram consumo de ração superior ao das fêmeas $(\mathrm{p}<0,05)$.

A tabela III indica os teores de fósforo e cálcio nas fezes e as concentrações séricas de fósforo, cálcio e ferro dos animais submetidos aos diferentes tratamentos. Não foi observado efeito de interação entre os fatores $(p>0,05)$.

Analisando-se a quantidade de fósforo e cálcio eliminados pelas fezes, observa-se que em relação ao fator FGMD, os animais que receberam as dietas com o co-produto eliminaram uma quantidade maior $(\mathrm{p}<0,05)$ de fósforo e cálcio nas fezes. Isso ocorreu porque a ligação do fitato com macro e micro-elementos ( $\mathrm{Ca}, \mathrm{Mg}, \mathrm{Fe}, \mathrm{Zn}, \mathrm{Cu}, \mathrm{Mn}$, Mo e Co) reduz a solubilidade e a biodisponibilidade dos nutrientes da ração, pois os complexos formados se precipitam e tornamse indisponíveis para o animal. Desta forma, os nutrientes não utilizados pelo animal são excretados pelas fezes, aumentando a deposição de minerais no meio ambiente (Lei e Porres, 2003).

Considerando o fator fitase, animais que receberam rações contendo a enzima tiveram um melhor aproveitamento do fósforo e do cálcio. Isso pode ser confirmado pela menor quantidade desses minerais nas fezes $(\mathrm{p}<0,05)$. O resultado desse estudo concorda com Figueirêdo et al. (2000) que utilizaram fitase e farelo de arroz integral em suas rações e também observaram redução na 


\section{PACHECO ETAL.}

Tabela III. Médias e (desvios-padrão) dos teores de fósforo e cálcio das fezes e da concentração sérica de fósforo, cálcio e ferro de suínos submetidos a tratamentos com e sem farelo de gérmen de milho desengordurado (FGMD) e com e sem fitase. (Means and (standard deviations) of the level of phosphorus and calcium in faeces and of serum phosphorus, calcium and iron concentration in pigs fed with and without defatted corn germ meal (FGMD) and with and without phytase).

\begin{tabular}{lccccc}
\hline & \multicolumn{2}{c}{ Fezes $(\mathrm{mg} / 100 \mathrm{~g})$} & \multicolumn{3}{c}{$\begin{array}{c}\text { Sangue }(\mathrm{mg} / \mathrm{dL}) \\
\text { Cálcio }\end{array}$} \\
\hline Sem FGMD & $1,55(0,5)^{\mathrm{b}}$ & $0,88(0,2)^{\mathrm{b}}$ & $9,25(1,6)$ & $10,24(1,3)$ & $210,50(74,3)$ \\
Com FGMD & $2,10(0,6)^{\mathrm{a}}$ & $1,03(0,3)^{\mathrm{a}}$ & $9,64(1,0)$ & $10,34(1,8)$ & $181,50(72,7)$ \\
Sem fitase & $2,26(0,4)^{\mathrm{a}}$ & $1,03(0,2)^{\mathrm{a}}$ & $9,12(1,2)$ & $10,16(1,7)$ & $180,81(51,6)$ \\
Com fitase & $1,38(0,4)^{\mathrm{b}}$ & $0,88(0,2)^{\mathrm{b}}$ & $9,78(1,4)$ & $10,41(1,4)$ & $215,43(91,5)$ \\
Machos castrados & $1,94(0,5)$ & $1,10(0,2)^{\mathrm{a}}$ & $9,43(1,2)$ & $10,19(1,4)$ & $189,14(43,0)$ \\
Fêmeas & $1,71(0,7)$ & $0,82(0,2) \mathrm{b}$ & $9,44(1,5)$ & $10,39(1,7)$ & $203,81(93,8)$ \\
CV $(\%)$ & 13,7 & 14,7 & 14,4 & 8,9 & 37,9 \\
\hline
\end{tabular}

ab Letras distintas nas colunas, para cada fator, indicam diferença $(p<0,05)$.

excreção de fósforo. Simons et al. (2005) constataram que a adição de fitase microbiana (1000 FTU) para suínos em crescimento reduziu a excreção de fósforo em $35 \%$. A fitase atua nas ligações do grupo fosfato, liberando fósforo e outros minerais que fazem parte dessa molécula (Moreira et al., 2003). Essa diminuição na excreção de elementos como nitrogênio, fósforo e cálcio por suínos em terminação é de extrema importância, pois ameniza a carga de poluição ambiental. Este fato é importante, pois comprova que independentemente da dieta apresentar mais ou menos ácido fítico $(2,98 \%$ na dieta sem FGMD e 4,85\% na dieta com FGMD) a fitase melhorou o aproveitamento destes minerais.

Em relação ao fator gênero, machos castrados eliminaram uma quantidade maior de cálcio nas fezes $(\mathrm{p}<0,05)$. Segundo McDowell (1992), as fezes são a principal via de excreção do cálcio, sendo o cálcio das fezes resultado do cálcio não absorvido da dieta, e da secreção intestinal desse elemento. Possivelmente a maior excreção de cálcio pelos machos castrados está relacionada às diferenças na metabolização do mineral entre os gêneros, de tal forma que o excesso do mineral foi excretado pelas fezes dos animais.

Não houve diferença estatística $(p>0,05)$ para as concentrações séricas de fósforo, cálcio e ferro. De acordo com Figueirêdo et al. (2000), a ação da enzima fitase também não influenciou o fósforo do plasma, o que difere de Young et al. (1993), que constataram aumento na concentração de fósforo no plasma com o aumento dos níveis de fitase nas dietas (0, 500 e 1000 FTU).

Almeida (2007), trabalhando com dietas com fitase e níveis reduzidos de fósforo para suínos em terminação, não encontraram diferenças significativas $(p>0,05)$ para as concentrações de ferro sérico. Todavia, Gebert et al. (1999) observaram que animais que receberam dietas com fitase (1000 FTU) apresentaram aumento na concentração plasmática de ferro $(\mathrm{p}<0,05)$ e de fósforo $(\mathrm{p}<0,001)$.

A presença de fitatos, oxalatos e fosfatos formam complexos com o ferro, retardando 


\section{ÁCIDO FÍTICO E FITASE NA DIETA DE SUÍNOS}

sua absorção. O ferro é vital para todas as células e está incluído no grupo heme de citocromos, peroxidases, catalases, mioglobina e hemoglobina. Por outro lado, o ferro pode lesar diferentes tecidos por catalisar a reação que converte peróxidos de oxigênio em íons radicais livres, que destroem a membrana celular, proteínas e o DNA (Zago et al., 2001;Hentze et al., 2004). Considerando que o excesso e a deficiência de ferro podem causar morte celular, os níveis desse elemento devem ser controlados. Os valores de referência para o ferro, segundo Kaneko et al. (1997) são de 91-199 $\mu \mathrm{g} / \mathrm{dL}$.

Os resultados referentes ao hemograma na tabela IV indicam que não houve diferença entre os tratamentos para os fatores FGMD, fitase ou gênero. Todos os valores encontrados permaneceram dentro dos de referência, de acordo com Kaneko et al. (1997), indicando que não houve comprometimento da maior presença do ácido fítico na dieta e da fitase sobre estas características.
Para as proteínas plasmáticas totais (PTP), os machos castrados apresentaram valores ligeiramente superiores aos das fêmeas, porém, esses valores encontram-se dentro da normalidade, que seria em torno de 7,9-8,9 g/dL. Em relação ao fibrinogênio não houve diferença $(\mathrm{p}<0,05)$ entre os fatores. Todavia houve interação entre os fatores gênero e fitase para as características hematócrito e hemoglobina mostrados abaixo na tabela $\mathbf{V}$.

Os resultados indicam que na ausência da fitase, as fêmeas apresentaram valores menores $(\mathrm{p}<0,05)$ de hematócrito e hemoglobina em relação aos machos. Quando se comparam as fêmeas, nota-se que as dietas que continham fitase aumentaram ligeiramente as mesmas variáveis citadas, porém, os valores apresentados permaneceram dentro dos valores normais para a espécie suína, que são de $32-50 \%$ para o hematócrito e $10-16 \mathrm{~g} / \mathrm{dL}$ para a hemoglobina.

Em relação às variáveis triglicerídeos,

Tabela IV. Médias e (desvios-padrão) dos valores de hemácia, volume corpuscular médio (VCM), hemoglobina corpuscular média (HCM), concentração de hemoglobina corpuscular média (CHCM), proteína total plasmática (PTP) e fibrinogênio do sangue de suínos submetidos a tratamentos com e sem farelo de gérmen de milho desengordurado (FGMD) $e$ com e sem fitase. (Means and (standard deviations) of red blood cells, mean corpuscular volume (VCM), mean corpuscular hemoglobin (HCM), mean corpuscular hemoglobin concentration (CHCM), total plasma protein (PTP) and fibrinogen values from the blood of pigs fed with and without defatted corn germ meal (FGMD) and with and without phytase).

\begin{tabular}{lcccccc}
\hline Fatores & $\begin{array}{c}\text { Hemácias } \\
\left(\times 10^{6} / \mu \mathrm{L}\right)\end{array}$ & $\begin{array}{c}\mathrm{VCM} \\
(\mathrm{fL})\end{array}$ & $\begin{array}{c}\mathrm{HCM} \\
(\mathrm{pg})\end{array}$ & $\begin{array}{c}\mathrm{CHCM} \\
(\%)\end{array}$ & $\begin{array}{c}\text { PTP } \\
(\mathrm{g} / \mathrm{dL})\end{array}$ & $\begin{array}{c}\text { Fibrinogênio } \\
(\mathrm{mg} / \mathrm{dL})\end{array}$ \\
\hline SemFGMD & $6,4(1,0)$ & $58,6(9,2)$ & $19,0(2,6)$ & $32,6(1,4)$ & $8,0(0,4)$ & $406,2(161,1)$ \\
Com FGMD & $6,6(0,8)$ & $57,8(6,1)$ & $18,6(2,1)$ & $32,3(1,2)$ & $8,2(0,4)$ & $562,5(294,1)$ \\
& & & & & & \\
Sem fitase & $6,4(1,0)$ & $58,4(8,3)$ & $18,8(2,7)$ & $32,3(1,0)$ & $8,1(0,4)$ & $475,0(220,6)$ \\
Com fitase & $6,6(0,9)$ & $58,0(7,4)$ & $18,9(1,9)$ & $32,6(1,5)$ & $8,1(0,4)$ & $493,7(276,8)$ \\
M. castrados & $6,6(1,0)$ & $58,8(9,4)$ & $18,9(2,8)$ & $32,3(1,3)$ & $8,2(0,4)^{\mathrm{a}}$ & $418,7(213,6)$ \\
Fêmeas & $6,5(0,9)$ & $57,5(5,7)$ & $18,8(1,8)$ & $32,6(1,3)$ & $7,9(0,4)^{\mathrm{b}}$ & $550,0(265,8)$ \\
CV $(\%)$ & 13,8 & 13,5 & 12,7 & 4,3 & 4,6 & 50,9 \\
\hline
\end{tabular}

ab Letras distintas nas coluna, para cada fator, indicam diferença $(p<0,05)$. 


\section{PACHECO ETAL.}

Tabela $\boldsymbol{V}$. Interação entre fitase e gêneros para os parâmetros hematócrito e hemoglobina do sangue de suínos submetidos a tratamentos com e sem farelo de gérmen de milho desengordurado (FGMD) e com e sem fitase. (Interaction of phytase and sex on the hematocrit and hemoglobin parameters from the blood of pigs fed with and without defatted corn germ meal (FGMD) and with and without phytase).

\begin{tabular}{|c|c|c|c|}
\hline Fatores & Sem fitase & Com fitase & CV (\%) \\
\hline \multicolumn{4}{|l|}{ Hematócrito (\%) } \\
\hline Machos castrados & $39,00(2,5)^{\mathrm{aA}}$ & $36,75(3,2)^{) \mathrm{aA}}$ & 7,4 \\
\hline Fêmeas & $34,37(2,1)^{\mathrm{bB}}$ & $39,37(3,1)^{\mathrm{aA}}$ & 6,0 \\
\hline \multicolumn{4}{|l|}{ Hemoglobina (g/dL) } \\
\hline Machos castrados & $12,57(1,0)$ aA & $11,85(1,0)^{\mathrm{aA}}$ & 8,6 \\
\hline Fêmeas & $11,35(0,9)^{\mathrm{bB}}$ & $12,72(1,2)^{\mathrm{aA}}$ & 7,2 \\
\hline
\end{tabular}

colesterol e ureia observou-se diferença apenas para a concentração de uréia entre os gêneros, sendo que os machos castrados apresentaram maiores $(\mathrm{p}<0,05)$ teores quando comparados às fêmeas como mostra a tabela VI.

De acordo com Minihane e Rimbach (2002), o ácido fítico atua diminuindo os níveis de triglicerídeos e colesterol no plasma, fato que não foi confirmado neste experimento.

Fialho et al. (2004) determinaram as concentrações de uréia plasmática ao suplementar níveis crescentes de fitase $(0$, 400, 800 e 1200 FTU) na ração de suínos em crescimento. Os autores observaram efeito

Tabela VI. Médias e (desvios-padrão) dos valores de triglicerídeos, colesterol e uréia do sangue de suínos submetidos a tratamentos com e sem farelo de gérmen de milho desengordurado (FGMD) e com e sem fitase. (Means and (standard deviations) of triglycerides, cholesterol and urea values from the blood of pigs fed with and without defatted corn germ meal (FGMD) and with and without phytase).

\begin{tabular}{lccc}
\hline & Triglicerídeos $(\mathrm{mg} / \mathrm{dL})$ & Colesterol & Uréia \\
\hline Sem FGMD & $62,3(16,2)$ & $88,0(9,6)$ & $39,9(31,6)$ \\
Com FGMD & $69,7(18,2)$ & $96,5(16,0)$ & $37,7(16,4)$ \\
Sem Fitase & $64,9(21,0)$ & $92,3(17,1)$ & $34,4(13,1)$ \\
Com Fitase & $67,1(13,3)$ & $92,2(9,5)$ & $43,2(32,5)$ \\
Machos castrados & $61,2(19,5)$ & $93,4(14,0)$ & $47,3(29,4)^{\mathrm{a}}$ \\
Fêmeas & $70,7(13,9)$ & $91,1(13,6)$ & $30,3(15,8)^{\mathrm{b}}$ \\
CV $(\%)$ & 22,4 & 13,4 & 57,9 \\
\hline
\end{tabular}

${ }^{a b}$ Letras distintas nas coluna, para cada fator, indicam diferença $(p<0,05)$.

Archivos de zootecnia vol. 61, núm. 236, p. 606. 


\section{ÁCIDO FÍTICO E FITASE NA DIETA DE SUÍNOS}

quadrático, com ponto de mínima concentração de uréia para 750 FTU, indicando que o uso da enzima pode ter aumentado o aproveitamento de proteínas da dieta, determinando assim, a diminuição dos valores de uréia no plasma. Isso porque a taxa de síntese da uréia é influenciada pelos valores de proteína da dieta e pelo catabolismo protéico. Se o animal ingere proteína em qualidade e quantidade adequadas às suas exigências, espera-se baixa excreção de nitrogênio com diminuição dos custos e da poluição ambiental. No presente experimento, os dois gêneros receberam a mesma quantidade de proteína na dieta, porém, como as exigências de proteína bruta para os machos são menores, provavelmente, o excesso de nitrogênio foi excretado pelas fezes dos machos castrados, aumentando, consequentemente os valores de uréia nos dejetos desses animais.

A análise dos resultados referentes ao peso e ao rendimento das carcaças apresentados na tabela VII revelou ausência de diferença $(p>0,05)$ entre os fatores FGMD e fitase, porém, em relação aos gêneros, os machos apresentaram maior peso vivo final, peso de carcaça quente e peso de carcaça resfriada. As fêmeas, porém, apresentaram maior rendimento de carne na carcaça $(p<0,05)$. A diferença de deposição dos tecidos entre os gêneros é um fator determinante no rendimento de carcaça e de carne na carcaça. À medida que aumenta a deposição de tecido adiposo na carcaça, a proporção de carne diminui.

Os resultados referentes à avaliação quantitativa das carcaças na tabela VIII indicam que não foram observadas diferenças $(p>0,05)$ em relação aos fatores FGMD e fitase. Também não houve interação entre os fatores.

De acordo com Moreira et al. (2002), os níveis crescentes de FGMD nas rações de suínos, em fase de crescimento e terminação levaram à redução da espessura de toucinho e não afetaram a profundidade do lombo. Silva et al. (2004) não observaram influência da inclusão do FGMD sobre as características de carcaça, indicando que esse produto

Tabela VII. Médias e (desvios-padrão) das variáveis peso vivo final $(P V)$, peso da carcaça quente $(P C Q)$, peso da carcaça resfriada $(P C R)$, rendimento de carcaça $(R C)$ e rendimento de carne na carcaça resfriada $(R C C)$ de suínos submetidos a tratamentos com e sem farelo de gérmen de milho desengordurado (FGMD) e com e sem fitase. (Means and (standard deviations) of final body weight (PV), hot carcass weight (PCQ), chilled carcass weight (PCR), carcass yield $(R C)$ and meat yield of the chilled carcass (RCC) of pigs fed with and without defatted corn germ meal (FGMD) and with and without phytase).

\begin{tabular}{lccccc}
\hline & PV $(\mathrm{kg})$ & $\mathrm{PCQ}(\mathrm{kg})$ & $\mathrm{PCR}(\mathrm{kg})$ & $\mathrm{RC}(\%)$ & $\mathrm{RCC}(\mathrm{kg})$ \\
\hline Sem FGMD & $86,5(8,6)$ & $65,5(6,7)$ & $63,7(6,6)$ & $75,8(1,6)$ & $62,9(2,8)$ \\
Com FGMD & $87,9(5,4)$ & $66,5(4,5)$ & $64,8(4,4)$ & $75,7(1,6)$ & $63,0(2,5)$ \\
& & & & & \\
Sem fitase & $87,0(7,5)$ & $65,7(5,4)$ & $63,9(5,3)$ & $75,5(1,5)$ & $62,9(2,1)$ \\
Com fitase & $87,3(6,9)$ & $66,3(6,0)$ & $64,5(5,9)$ & $75,9(1,7)$ & $63,1(3,1)$ \\
Machos castrados & $90,2(4,4)^{\mathrm{a}}$ & $68,6(4,3)^{\mathrm{a}}$ & $66,7(4,3)^{\mathrm{a}}$ & $76,0(1,9)$ & $61,6(2,8)^{\mathrm{b}}$ \\
Fêmea & $84,2(8,1)^{\mathrm{b}}$ & $63,5(5,8)^{\mathrm{b}}$ & $61,7(5,6)^{\mathrm{b}}$ & $75,4(1,2)$ & $64,3(1,6)^{\mathrm{a}}$ \\
CV (\%) & 6,1 & 6,4 & 6,4 & 1,5 & 2,9 \\
\hline
\end{tabular}

${ }^{a b}$ Letras distintas nas colunas, para cada fator, indicam diferença $(p<0,05)$. 
Tabela VIII. Médias e (desvios-padrão) das variáveis comprimento de carcaça (CC), profundidade de músculo $(P M)$, espessura de toucinho $(E T)$ e área de olho do lombo (AOL) de suínos submetidos a tratamentos com e sem farelo de gérmen de milho desengordurado (FGMD) e com e sem fitase. (Means and (standard deviations) of carcass length (CC), muscle depth (PM), backfat thickness (ET) and loin eye area (AOL) of pigs fed with and without defatted corn germ meal (FGMD) and with and without phytase).

\begin{tabular}{lcccc}
\hline & CC $(\mathrm{cm})$ & PM $(\mathrm{mm})$ & ET $(\mathrm{mm})$ & AOL $\left(\mathrm{cm}^{2}\right)$ \\
\hline Sem FGMD & $89,0(4,3)$ & $59,62(5,6)$ & $10,09(4,2)$ & $38,47(4,3)$ \\
Com FGMD & $90,1(3,0)$ & $60,39(5,6)$ & $9,94(3,4)$ & $38,41(4,1)$ \\
& & & & \\
Sem fitase & $89,0(4,5)$ & $58,84(4,0)$ & $10,00(3,1)$ & $37,14(2,9)$ \\
Com fitase & $90,1(2,6)$ & $61,17(6,6)$ & $10,03(4,5)$ & $39,74(4,8)$ \\
Machos castrados & $89,7(3,1)$ & $60,94(4,0)$ & $12,00(3,2) \mathrm{b}$ & $37,95(4,8)$ \\
Fêmeas & $89,4(4,2)$ & $59,07(6,7)$ & $8,03(2,4) \mathrm{a}$ & $38,94(3,3)$ \\
CV $(\%)$ & 3,5 & 9,5 & 25,5 & 10,3 \\
\hline
\end{tabular}

${ }^{a b}$ Letras distintas nas colunas, para cada fator, indicam diferença $(p<0,05)$.

não levou a efeitos deletérios sobre as mesmas. As diferenças observadas entre vários experimentos que utilizaram o FGMD como ingrediente, revelam que as diferenças na composição do co-produto podem ter sido responsáveis pelos resultados distintos observados.

Para o fator fitase, os resultados foram semelhantes aos obtidos por Santos et al. (2008), que não verificaram diferença $(\mathrm{p}>0,05)$ para as variáveis espessura de toucinho, área de olho do lombo, comprimento de carcaça e peso da carcaça, mas demonstraram que a média de rendimento de carcaça dos animais que receberam ração com fitase e reduzido teor de fósforo foi superior à média dos animais que receberam ração sem adição de fitase. Os resultados foram similares aos de Fandrejewski et al. (1999) e Ludke et al. (2002), que também não encontraram efeito significativo nas características de carcaça dos animais alimentados com dietas suplementadas com fitase.

Para os dados de carcaça observa-se que houve diferença apenas entre os gêneros para a variável espessura de toucinho, indicando que as fêmeas apresentaram valores relativamente menores $(p<0,05)$ em relação aos machos para essa característica, possivelmente devido às diferenças fisiológicas próprias de deposição desse tecido, visto que machos castrados possuem maior tendência ao acúmulo de gordura, em relação às fêmeas.

\section{CONCLUSÕES}

$O$ farelo de gérmen de milho desengordurado (FGMD), como principal fonte de ácido fítico, promoveu maior consumo de ração pelos animais. A carcaça e parâmetros hematológicos não foram influenciadas pelos fatores FGMD e fitase. A fitase na ração foi efetiva na redução da excreção de $\mathrm{Pe}$ Ca pelas fezes, valorizando sua inclusão para a minimização da poluição ambiental e substituição de fontes não renováveis de $\mathrm{P}$. Em relação ao fator gênero, machos castrados apresentaram maior excreção de uréia, maiores pesos de carcaça e de espessura de toucinho. Fêmeas apresentaram maior rendimento de carne na carcaça. 


\section{ÁCIDO FÍTICO E FITASE NA DIETA DE SUÍNOS}

\section{BIBLIOGRAFIA}

Almeida, R.F. 2007. Ferro e imunidade humoral em suínos alimentados com fitase e níveis reduzidos de fósforo. Ciên Anim Bras, 8: 767-776.

Beers, S. and Jongbloed, A.W. 1992. Apparent overall (total tract) digestibility of $\mathrm{P}$ in relation to doses of Aspergillus niger phytase in diets for pigs. J Anim Sci, 70: 242.

Bohn, L., Meyer, A.S. and Rasmussen, S.K. 2008. Phytate: impact on environment and human nutrition. A challenge for molecular breeding. $J$ Zhej Uni Sci B, 9: 165-191.

Bridi, A.M. e Silva, C.A. 2007. Métodos de avaliação da carcaça e da carne suína. Midiograf. Londrina. 97 pp.

Castillon, P. 2005. Le phosphore: sources, flux et roles pour la production végétale et l'eutrophisation. INRA Productions Animales, 18: 153158.

Chen, P.S., Toribara, T.Y. and Warner, H. 1956. Microdetermination of phosphorus. Analit Chem, 28: 1756-1758.

Fandrejewski, H., Weremko, D., Raj, S., Skiba, G. and Han, I.K. 1999. Performance, body and carcass composition and bone characteristics of pigs fed rapeseed and soybean meal-cereal diets supplemented with microbial phytase. J Anim Feed Sci, 8: 533-547.

Fialho, E.T., Silva, H.O., Lima, J.A.F., Lara, L.B., Viera Neto, J. e Silva, L.F. 2004. Efeito da fitase sobre o desempenho, e teor de uréia no plasma de suínos na fase de crescimento. In: Reunião Anual da Sociedade Brasileira de Zootecnia, no 41. Anais... Embrapa Gado de Corte. Campo Grande.

Figueirêdo, A.V., Fialho, E.T. e Vitti, D.M.S.S. 2000. Ação da fitase sobre a disponibilidade biológica do fósforo, por intermédio da técnica de diluição isotópica, em dietas com farelo de arroz integral para suínos. Rev Bras Zootecn, 29: 177-182.

Fireman, F.A.T. e Fireman, A.K.B.A.T. 1998. Enzimas na alimentação de suínos. Ciên Rural, 28: 173-178.

Freitas, R.M. 1998. Fontes alternativas para o milho. In: Seminário Nutron de Suinocultura, 2. Anais... NUTRON. Campinas-SP. pp. 15-24.

Gebert, S., Bee, G., Pfirter, H.P. and Wenk, C. 1999. Phytase and vitamin $E$ in the feed of growing pigs: 1 . Influence on growth, mineral digestibility and fatty acids in digesta. $J$ Anim Phys Anim Nutr, 81: 9-19.

Guidoni, A.L. 2000. Melhoria de processos para tipificação e valorização de carcaças suínas no Brasil. In: Conferência Internacional VirQualidade da Carne Suína. Anais... EMBRAPA-CNPSA. Concórdia. pp. 221-234.

Harbach, A.P., Costa, M.C.R., Soares, A.L., Bridi, A.M., Shimokomaki, M., Silva, C.A. and Ida, E.I. 2007. Dietary corn germ containing phytic acid prevents pork meat lipid oxidation while maintaining normal animal growth performance. Food Chem, 100: 1630-1633.

Hentze, W.M., Muckenthaler, M.U. and Andrews, N.C. 2004. Balancing acts: molecular control of mammalian iron metabolism. Cell, 117:285-297.

Kaneko, J.J., Harvey, J.W. and Bruss, M.L. 1997. Clinical biochemistry of domestic animals. $5^{\underline{a}} \mathrm{ed}$. Academic Press. London.

Ketaren, P.P., Battherham, E.S., Dettmann, E.B. and Farrell, D.J. 1993. Phosphorus studies in pigs: 3 . Effect of phytase supplementation on the digestibility and avaibility of phosphorus in soya-bean meal for grower pigs. Brit J Nutr, 70: 289-311.

Lei, X.G. and Porres, J.M. 2003. Phytase enzymology, applications, and biotechnology. Biotec Letters, 25: 1787-1794.

Lopez, H.W., Leenhardt, F., Coudray, C. and Remesy, C. 2002. Minerals and phytic acid interactions: is it a real problem for human nutrition? Inter J Food Sci Tech, 37: 727-739.

Ludke, M.C.M., López, J. e Ludke, J.V. 2002. Fitase em dietas para suínos em crescimento: (1) parâmetros de carcaça e ossos. Ciên Rural, 32: 97-102.

Malavolta, E., Vitti, G.C. e Oliveira, S.A. 1992. Avaliação do estado nutricional das plantas: princípios e aplicação. $2^{\mathrm{a}}$ ed. Potafós. São Paulo $234 \mathrm{pp}$.

McDowell, L.R. 1992. Minerals in animal and human nutrition. Academic Press. New York. 232 pp.

Minihane, A.M. and Rimbach, G. 2002. Iron absorption and the iron binding and anti-oxidant properties of phytic acid. Inter J Food Sci Tech, 37: 741-748.

Moreira, I., Ribeiro, C.R., Furlan, C., Scapinello, C. e Kutschenko, M. 2002. Utilização do farelo de 


\section{PACHECO ETAL.}

gérmen de milho desengordurado na alimentação de suínos em crescimento e terminação digestibilidade e desempenho. Rev Bras Zootecn, 31: 2238-2246.

Moreira, J.A., Vitti, D.M.S.S., Lopes, J.B. e Trindade Neto, M.A. 2003. Biodisponibilidade e perdas endógenas mínimas de $\mathrm{P}$ em dietas com níveis crescentes de fitase para suínos em crescimento pela técnica de diluição isotópica. Arq Bras Med Vet Zootec, 55: 350-356.

NRC. 1998. Nutrient Requirement of Swine. $10^{\text {th }} \mathrm{ed}$. National Academic of Sciences. Washington.

Pointillart, A. 1997. Importância dos fitatos e das fitases na alimentação dos suínos. Hora Vet, 95: 66-72.

SAEG. 1997. Sistema de análises estatísticas e genéticas. Versão 7.1. Universidade Federal de Viçosa-UFV. Viçosa, MG. 150 pp.

Santos, S.P., Nunes, R.C, Lopes, E.L., Roner, M.N.B., Stringhini, J.H., Oliveira, A.P.A. e Rufino, L.M. 2008. Retirada do suplemento micro mineral, redução de fósforo inorgânico e adição de fitase em rações de suínos na fase de terminação. Ciên Anim Bras, 9: 663-671.

Selle, P.H., Ravindran, R.A., Caldwell, R.A. and Bryden, W.L. 2000. Phytate and phytase: consequences for protein utilization. Nutr Res
Rev, 13: 255-248.

Selle, P.H. and Ravindran, V. 2008. Phytatedegrading enzymes in pig nutrition. Lives Sci, 133: 99-122.

Silva, F.C. 1999. Manual de análises químicas de solo, plantas e fertilizantes. EMBRAPA. Brasília. $370 \mathrm{pp}$.

Silva, H.O., Fialho, E.T., Freitas, R.T.F., Lima, J.A.F., Logato, P.R.V. and Schoulten, N.A. 2004. Phytase in rations of growing pigs: performance, blood parameters and bone mineral content. Ciên Agrotec, 28: 1428-1436.

Simons, P.C.M., Versteegh, A.J., Jongbloed, A.W., Kemme, P.A., Slump, P., Bos, K.D., Wolters, M.G., Beudeker, R.F. and Verschoor, G.J. 2005. Improvement of phosphorus availability by microbial phytase in broilers and pigs. Brit $J$ Nutr, 93: 136-152.

Thompson, D.B. and Erdman, J.W. 1982. Phytic acid determination in soybeans. J Food Sci, 47: 513-517.

Young, G.L., Leunisen, M. and Atkinson, J.L. 1993. Addition of microbial phytase to diets of young pigs. J Anim Sci, 71: 2147-2150.

Zago, M.A., Falcão, R.P. e Pasquini, R. 2001. Hematologia: fundamentos e prática. Atheneu. São Paulo. 1081 pp. 